\title{
BRIEF CHARACTERISTIC OF BLOOD MORPHOLOGY CHANGES CAUSED IN BROILER TURKEYS BY DIETARY PROBIOTICS VETOM 1.1, Se-CONTAINING SEL-PLEX AND THEIR COMBINED APPLICATION
}

\section{A.I. SHEVCHENKO ${ }^{1,}$, , S.A. SHEVCHENKO ${ }^{1}$}

1Gorno-Altai State University, 1, ul. Lenkina, Gorno-Altaisk, Altai Republic, 649000 Russia, e-mail shaisol60@mail.ru, shevchenko2011@list.ru;

${ }^{2}$ Gorno-Altai Research Institute of Agriculture, Federal Agency of Scientific Organizations, 2, ul. Katunskaya, Maima village, Altai Republic, 649100 Russia

Received June 1, 2015

\section{Abstract}

Optimal physiological state and further performance of genetically determined production efficacy in young farm animals and poultry significantly depend on application of probiotics used to correct gut microbiota number and composition, and enough input of essential microelements such as Se. Their mutual effect on metabolism, and animal and poultry productivity is under special consideration. An impact of probiotis on mineral metabolism is being reported in detail while the study of the Se metabolism in macroorganism as influenced by the probiotic preparation are extremely restricted. Blood morphology parameters, being universal in character and easy evaluated, are good to estimate the metabolic state. In this paper we report the results of estimating blood erythrocyte and leukocyte number, hemoglobin levels, erythrocyte sedimentation, hematocrit, an average total and percentage hemoglobin level per erythrocyte, and an average erythrocyte size in groeing broiler turkeys (Meleagris gallopavo) of But 8 cross on day 50 and day 100 of life. Poultry was reared under the commercial farm conditions (Yasnogorskii brunch of ALPI agro holding, Kemerovo Province). Russian Vetom 1.1 probiotics, Sel-Plex («Alltech», Ireland) which contains organic Se compounds and their combination were administrated to chicken additionally to the standard basic diet. All tested preparation and schemes had no negative impact on studied blood parameters. There was a clear tendency to increased erythrocyte and leukocyte numbers, together with hemoglobin level and hematocrit value though the parameters remained within physiological limits. These indicate the hematopoietic stimulation which can promote active metabolism. The positive effect of synbiotics (i.e., probiotics and Se combination) was more pronounces. The growing broiler turkeys administrated with dietary synbiotics were superior to those fed with probiotics or SelPlex. Particularly, their blood erytrocyte number was 1.6, $2.4 \%$ and 1.1, $4.4 \%$ higher, the hemoglobin level was $0.3,2.2 \%$ and $0.9,4.0 \%$ higher, the leukocyte number was 5.6, $8.2 \%$ and 5.3, $7.0 \%$ higher, and hematocrit was $0.6,2.5 \%$ and $0.6,1.8 \%$ higher on day 50 and day 100, respectively.

Keywords: probiotics, synbiotics, Vetom 1.1, selenium, Sel-Plex, broiler turkeys, Meleagris gallopavo, blood morphology indexes.

Optimization of physiological processes in young farm animals and poultry is largely achieved by probiotics used to correct the species and quantitative composition of gastrointestinal microflora [1-4]. In addition, a sufficient input of essential trace elements, such as selenium, is one of the most significant factors contributing to the realization of genetic potential in poultry. The combined effect of probiotics and selenium on metabolism and productivity becomes the subject of the special attention of researchers. Biochemical functions of selenium are associated with its catalytic role and are to regulate the rate of redox processes, as well as of the reactions involving enzymes, vitamins, and hormones. Small doses of selenium stimulate the activity of many mammalian enzymatic systems, thus enhancing the processes of biological oxidation and phosphorylation. The antioxidant effect of selenium is due to its inclusion in the active selenium-dependent glutathione peroxidase site and, possibly, to the capability of selenium containing amino acids that act as free radical quenchers 
or participate in non-radical decomposition of lipid peroxides, of an independent anti-oxidant effect [5-7]. Selenium deficiency causes the symptoms of hypothyroidism which results in a decrease in metabolic processes intensity, and consequently, in the reduction of animal and poultry productivity [8-12].

The effect of probiotics on mineral metabolism is described in publications, but there is almost no data on their effect on the metabolism of selenium in macroorganisms [13-15]. The effectiveness of probiotics in the poultry industry and their stimulating effect on the growth, development and performance in poultry have been demonstrated [16-21].

The physicochemical and morphological blood parameters, the content of nutritive compounds and metabolic products in blood depend on poultry species, age, physiological state, and feeding conditions. The morphological parameters of blood can be used to assess the state of metabolic processes [22-24].

The purpose of this work was the study of the impact of Russian Vetom 1.1 probiotic, organic selenium (Sel-Plex preparation) and a synbiotic based on the combination of the above products on the morphological blood parameters in growing turkeys broilers.

Technique. The experiments were performed in «Siberian province» Poultry Farm, the Yasnogorsk branch of Agro Holding «ALPI» (Kemerovo Province, Kemerovo Region). According to the principle of similar pairs [25], 1-day-old cross But 8 Meleagris gallopavo turkey broilers were divided into the control and three experimental groups (30 specimens per group), the growing period duration was 124 days. Group I turkeys were administrated with Vetom 1.1 («Research Center», Novosibirsk Region) as a part of the basic diet at a dose of $75 \mathrm{mg} / \mathrm{kg}$ body weight once a day for 10 days, the second cycle was conducted in 20 days. Group II turkeys were given Se as Sel-Plex (Alltech, Ireland) at $0.3 \mathrm{mg} / \mathrm{kg}$ feed once a day for 10 days, the second cycle was conducted in 20 days. The basic diet of group III was supplemented with synbiotic (Vetom 1.1 at a dose of $75 \mathrm{mg} / \mathrm{kg}$ body weight + Se from Sel-Plex in the amount of $0.3 \mathrm{mg} / \mathrm{kg}$ feed) once a day for 10 days, the cycle was repeated in 20 days to the end of growing period. The products were not administered in the control group (C).

Blood was collected from turkeys on day 1 of life directly from the heart and then on days 50 and 100 from the wing vein. In all cases, blood was collected in the morning prior to feeding with Trilon B as an anticoagulant.

Blood morphological parameters were determined by conventional methods. Erythrocyte number was measured nephelometrically by FEC KFK-3 (Russia); hemoglobin was recorded by FEC KFK-3 using hemoglobin cyanide method; erythrocyte sedimentation rate was studied using Panchenkov micromethod; number of leukocytes was counted in Goryaev's chamber; hematocrit was estimated by centrifugation; mean absolute corpuscular hemoglobin, mean percentage of corpuscular hemoglobin, and mean corpuscular volume were calculated [26, 27].

Biometric processing of experimental data was performed using standard Microsoft Excel software. Significance was assessed by Student's $t$-test. The calculations were performed according to the algorithms set forth in the respective manuals [28-30].

Results. Vetom 1.1 is a immobilized dried spore biomass of plasmidtransfected strain VKPM V-10641 Bacillus subtilis, producing $\alpha-2$ interferon. SelPlex is produced based on the yeast cell extract, and contains Se mainly in the selenomethionine $(50 \%)$ and selenocysteine $(25 \%)$ amino acids with the total selenium content of $1000 \mathrm{mg} / \mathrm{kg}$.

In the day 1 of life, the parameters studied were not significantly different 
in the control and experiment poultry (Table).

Dynamics of blood morphological parameters in cross But 8 turkeys (Meleagris gallopavo) under application of probiotic Vetom 1.1, Se-containing Sel-Plex, and a synbiotic based on the combination of the above products $(M \pm m$, «Siberian province» Poultry Farm, the Yasnogorsk branch of Agro Holding «ALPI», Kemerovo Province, Kemerovo Region)

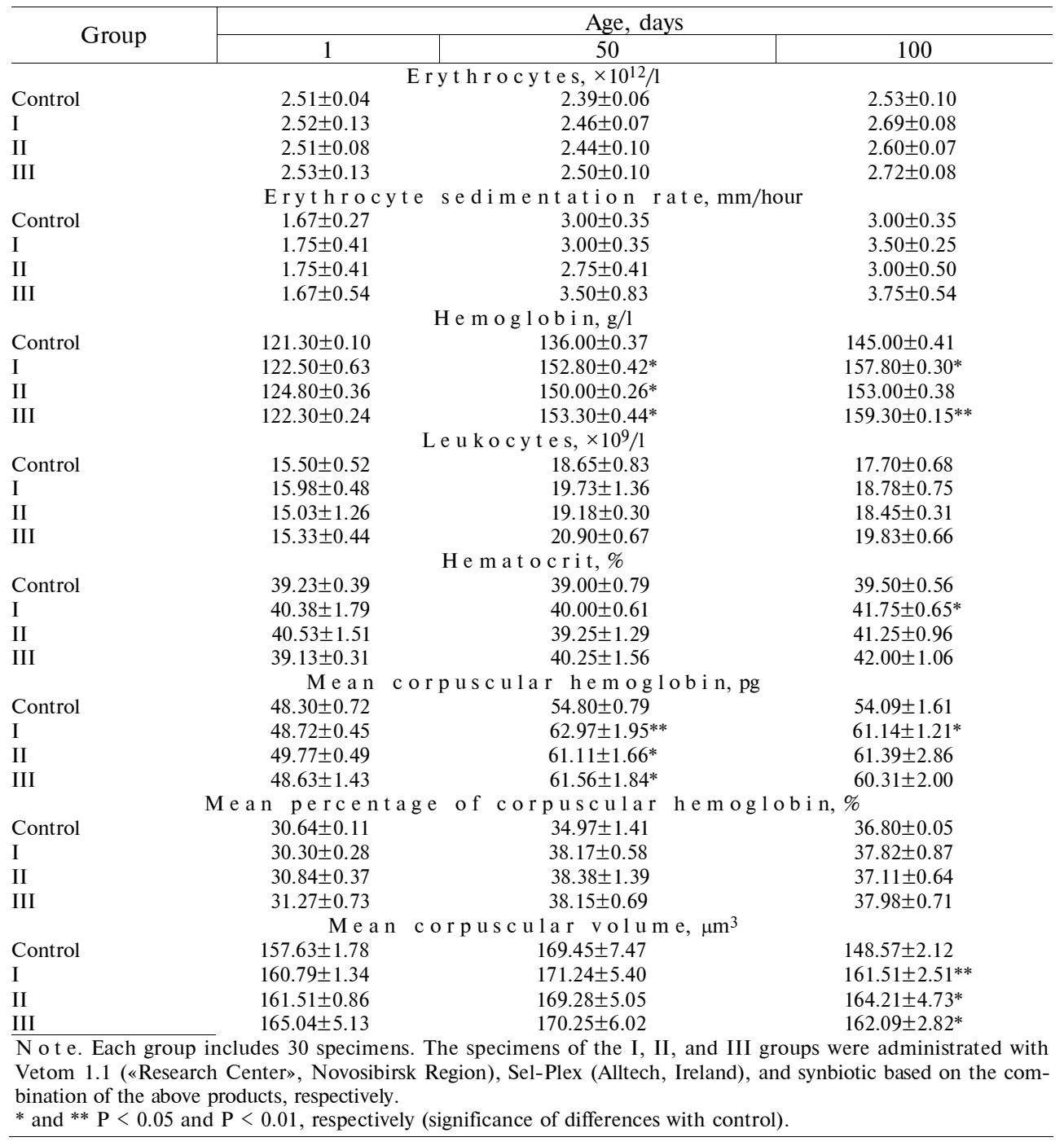

Erytrocyte numbers were found to be 3.0 and $6.3 \%$ higher in the group I turkeys at days 50 and 100, respectively, compared to control. Erythrocyte sedimentation rate had no significant differences in the experimental and control groups. Hemoglobin levels in experimental group turkey broilers at days 50 and 100 were higher by $12.4 \%(\mathrm{P}<0.05)$ and $8.8 \%(\mathrm{P}<0.05)$, respectively, than that in the control. At days 50 and 100, leukocyte numbers were 5.8 and $6.1 \%$ greater and hematocrit was 2.6 and $5.7 \%(\mathrm{P}<0.05)$ higher, respectively, in group I turkeys compared to control. Mean absolute corpuscular hemoglobin in this group was higher by $14.9 \%(\mathrm{P}<0.01)$ and $13.0 \%(\mathrm{P}<0.05)$, respectively, versus the control values, within the observation period; mean percentages of corpuscular hemoglobin increased by 9.2 and $2.3 \%$, and mean corpuscular volumes was $10.6 \%$ and $8.7 \%(\mathrm{P}<0.01)$ higher.

In group II compared to the control at days 50 and 100, erythrocyte 
numbers were 2.1 and $2.8 \%$ higher with hemoglobin levels $10.3 \%(\mathrm{P}<0.05)$ and $5.5 \%$ higher, leukocyte numbers 2.8 and $4.2 \%$ higher, hematocrit 0.6 and $4.4 \%$ higher, mean corpuscular hemoglobin $11.5 \%(\mathrm{P}<0.05)$ and $13.5 \%$ higher, and mean percentage of hemoglobin 9.8 and $8.4 \%$ higher, respectively; however, mean corpuscular volume at day 50 was lower compared to the control, while at day 100 it was $10.5 \%$ higher $(\mathrm{P}<0.05)$.

In the experimental group III turkeys, erythrocyte numbers increased by 4.6 and $7.5 \%$, hemoglobin levels were $12.7 \%(\mathrm{P}<0.05)$ and $9.9 \%(\mathrm{P}<0.01)$ higher, leukocyte numbers were 12.1 and $12.0 \%$ higher and hematocrit was 3.2 and $6.3 \%$ greater versus control at days 50 and 100, respectively. Mean corpuscular hemoglobin increased by $12.3 \%(\mathrm{P}<0.05)$ and $11.5 \%$, mean percentage of corpuscular hemoglobin was 9.1 and $3.2 \%$ higher, and mean corpuscular volume increased by 0.5 and $9,1 \%(\mathrm{P}<0.05)$, respectively.

So, supplementing broiler turkey diet with probiotic (Vetom 1.1), trace element selenium (Sel-Plex preparation) and a synbiotic based on the combination of the above products at the doses recommended for use, steadily increased the main blood morphological parameters studied (erythrocyte and leukocyte number, hemoglobin level, absolute corpuscular hemoglobin per erythrocyte, the average percentage of corpuscular hemoglobin, mean corpuscular volume and hematocrit level), maintaining them within the physiologically normal rang. The effect observed can be explained by the stimulating effect of the specified preparations on the hematopoiesis which is directly related to adaptive capacity under stress loads and to the realization of the genetic potential of growth, development and productivity, as well as metabolism.

The more pronounced positive effect of synbiotic should be noted. Thus, the experimental group III turkeys were superior to that of groups I and II in erythrocyte numbers by $1.6 ; 2.4 \%$ and $1.1 ; 4.4 \%$, in hemoglobin levels by 0.3 ; $2.2 \%$ and $0.9 ; 4.0 \%$, in leukocyte numbers by $5.6 ; 8.2 \%$ and $5.3 ; 7.0 \%$, in hematocrit by $0.6 ; 2.5 \%$ and $0.6 ; 1.8 \%$ at days 50 and 100 , respectively.

Thus, the use of Russian probiotic Vetom 1.1, selenium-containing SelPlex preparation, and a synbiotic based on the combination of the above products promoted hematopoiesis, which resulted in a steady tendency to an increase in the basic blood morphological parameters in broiler turkeys. Preparations had no negative impact on poultry. Therefore, the development and substantiation of schemes for the use of these products is of interest both for researchers and practically. The major morphological and functional hematological parameters of animals and poultry may be an informative criterion of the effectiveness of the formulations and technologies proposed.

\section{REFEREN CES}

1. Lutful Kabir S.M. The role of probiotics in th poultry industry. Int. J. Mol. Sci., 2009, 10(8): 3531-3546 (doi: 10.3390/ijms10083531).

2. Patterson J.A., B urkholder K.M. Application of prebiotics and probiotics in poultry production. Poult. Sci., 2003, 82(4): 627-631 (doi: 10.1093/ps/82.4.627).

3. Ushakova N.A., Nekrasov R.V., Pravdin V.G., Kravtsova L.Z., Bob rovsk a a O.I., P a v lov D.S. Fundamental'nye issledovaniya, 2012, 1: 184-192.

4. Neminushchaya L.A., Provotorova O.V., Eremets N.K., Nezhuta A.A., K r a s o c h k o P.A. Veterinariya i kormlenie, 2014, 6: 21-22.

5. Chauhan S.S., Celi P., Le ury B.J., D unche a F.R. High dietary selenium and vitamin E supplementation ameliorates the impacts of heat load on oxidative status and acid-base balance in sheep. J. Anim. Sci., 2015, 93(7): 3342-3354 (doi: 10.2527/jas.2014-8731).

6. G a lo c h k i n V.A., G a lo c h k i n a V.P. Sel'skokhozyaistvennaya biologiya [Agricultural Biology], 2011, 4: 3-15.

7. Z h a o X., Y a o H., F a n R., Z h a ng Z., X u S. Selenium deficiency influences nitric oxide and selenoproteins in pancreas of chickens. Boil. Trace Elem. Res., 2014, 161(3): 341-349 (doi: 
10.1007/s12011-014-0139-9).

8. Liu C.P., Fu J., Lin S.L., Wang X.S., Li S. Effects of dietary selenium deficiency on mRNA levels of twenty-one selenoprotein genes in the liver of layer chickens. Boil. Trace Elem. Res., 2014, 159(1-3): 192-198 (doi: 10.1007/s12011-014-0005-9).

9. Habibian M., Ghazi S., Moeini M.M., Abdolmohammadi A. Effects of dietary selenium and vitamin $\mathrm{E}$ on immune response and biological blood parameters of broilers reared under thermoneutral or heat stress conditions. Int. J. Biometeorol., 2014, 58(5): 741-752 (doi: 10.1007/s00484-013-0654-y).

10. Vila B., Est e ve-Garcia E., B rufa u J. Probiotic micro-organisms: 100 years of innovation and efficacy; modes of action. World's Poultry Sci. J., 2010, 66(3): 369-380 (doi: 10.1017/S0043933910000474).

11. La ck a K., Szeliga A. Significance of selenium in thyroid physiology and pathology. Pol. Merkur. Lekarski, 2015, 38(228): 348-353.

12. Nozdrin G.A., Fedorov Yu.N., Shevchenko S.A., Ivanova A.B., Shevchenko A.I. Produktivnost' ptitsy i kachestvo produktsii ptitsevodstva pri primenenii probiotikov klassa vetom i selena [Performance and product quality in poultry as influenced by Vetom probiotics and Se]. Novosibirsk, 2013.

13. Z e l e $\mathrm{n} \mathrm{s} \mathrm{k}$ a y a O.V. Obmen veshchestv, energiya ratsionov i myasnaya produktivnost' tsyplyatbroilerov pri skarmlivanii im selenosoderzhashchikh dobavok i probiotika batsell. Avtoreferat kandidatskoi dissertatsii [Metabolosim, energy of rations, and meat production in broiler chickens fed with Se-containing additives and probiotics Batsel. PhD Thesis]. Orenburg, 2011.

14. Nozdrin G.A., Kazantseva T.G., Nozdrin A.G. Vestnik Novosibirskogo gosudarstvennogo agrarnogo universiteta, 2012, 1(22-2): 123-127.

15. Kalavathy R., Abdullah N., Jalaludin S., Ho Y.W. Effects of Lactobacillus cultures on growth performance, abdominal fat desposition, serum lipids and weight of organs of broiler chickens. Brit. Poult. Sci., 2003, 44: 139-144.

16. C o x C.M., D a 11 o u 1 R.A. Immunomodulatory role of probiotics in poultry and potential in ovo application. Benef. Microbes, 2015, 6(1): 45-52 (doi: 10.3920/BM2014.0062).

17. Nozdrin G.A., Revkov N.V., Lelyak A.I., Lelyak A.A., Petrash M.G., Lu k" y a nov A.N. Dostizheniya nauki i tekhniki APK, 2012, 10: 58-60.

18. Wunes R.V., S cherer C., Silva W.T.M., Appelt M.D., Pozza P.C., Vili te s F.M. Evaluation of probiotics in feed for laying hens in the second cycle stance. Agr. Brasil. Med. Vet. Zootech., 2013, 65(1): 248-254.

19. Kral M., Angelovicova M., Mrazova L. Application of probiotics in poultry production. Anim. Sci. Biotechnol., 2012, 45(1): 55-57.

20. G a g gi a F., M a t a re 11 i P., B i a v a t i B. Probiotics and prebiotics in animal feeding for safe food production. Int. J. Food Microbiol., 2010, 141 Suppl. 1: S15-S28 (doi: 10.1016/j.ijfoodmicro.2010.02.031).

21. V o 1 k o v a I. Kombikorma, 2014, 2: 63-64.

22. G e r a s i m e n k o V.V., K o t k ov a T.V., N a z a ro va E.A. Fundamental'nye issledovaniya, 2011, 8: 88-89.

23. Sido rova A.L., T k a c he n k o M.G. Ptitsevodstvo, 2014, 6: 40-42.

24. Tarakanov B.V., Nikolicheva T.A., Manukhina A.I., Alshin V.V., Niku li n V.N., P a la g i n a T.E. Sel'skokhozyaistvennaya biologiya, 2007, 2: 87-93.

25. O v s y a n n k o v A.I. Osnovy opytnogo dela $v$ zhivotnovodstve [Basics of experimental work in animal husbandry]. Moscow, 1976.

26. M e n's hik ov V.V., D e le kt orskaya L.N., Z o lot nitsk a a R.P., Andre e va Z.M., Anki rskaya A.S., B a lakhovski I.S., B e lok i n itski D.V., Voropaeva S.D., Garanina E.N., Lukicheva T.I., Pletneva N.G., S molya nitski i A.YA. Laboratornye metody issledovaniya $v$ klinike [Laboratory tests in clinicsl practice]. Moscow, 1987.

27. Kond rakhin I.P. Metody veterinarnoi klinicheskoi laboratornoi diagnostiki [Methods of clinical laboratory diagnostics in veterinary]. Moscow, 2004.

28. Plokhinski i N.A. Rukovodstvo po biometrii dlya zootekhnikov [Biometry for zootechnicians]. Moscow, 1969.

29. M e rk u r'e v a E.K. Biometriya v selektsii i genetike sel'skokhozyaistvennykh zhivotnykh [Biometry in breeding and genetics of farm animals]. Moscow, 1970.

30. Z a itse v G.N. Metodika biometricheskikh raschetov [Methods of biometric calculation]. Moscow, 1973. 